\title{
Incorporating Real-Life Open-Ended Design Projects In A First Year Design Course
}

\author{
Leonard Lye, PEng, PhD, FCSCE, FEC \\ Associate Dean (Graduate Studies) \\ Faculty of Engineering and Applied Science \\ Memorial University of Newfoundland \\ llye@mun.ca
}

\begin{abstract}
At Memorial University, for the last several years, instructors of the first-year engineering design course have worked closely with the local chapter of the Tetra Society of North America to provide meaningful openended doable design projects that are needed by actual clients. Founded in 1987, The Tetra Society of North America is an independent non-profit charitable organization that recruits skilled technical volunteers to design and fabricate custom assistive devices for people with disabilities. In this paper, several projects that have been assigned to students in the past will be described and example solutions provided by students will also be shown. From the feedback of students, instructors, and clients, this collaboration with the Tetra Society has been very successful in providing real, needed, doable projects, with real clients for first year engineering students.
\end{abstract}

\section{Introduction}

It is often difficult to assign a meaningful open-ended engineering design project in the first year of an engineering program. The projects are often contrived by the instructor and at the end, the project is just another exercise in the design process and do not normally benefit anyone except maybe the students if they get a reasonable grade. To make design projects at the first-year more meaningful, it is important that students are assigned open-ended design projects that are doable, needed, and if successful would be of great benefit to an actual client. Students working on these projects would definitely be more motivated because of the real need and an actual client that is depending on them for a solution. At Memorial University, instructors of the first-year engineering design course have teamed up with the local chapter of the Tetra Society of North America to provide such open-ended design projects that are needed by actual Tetra clients.
In the next section, a history of the founding of the Tetra Society and how it works will be presented. This will be followed in Section 3 by a brief overview of the first-year engineering design course at MUN. Section 4 describes some of the projects that were assigned to the first year students and their resulting efforts. The conclusion is given in Section 5 followed by the acknowledgement and references.

\section{Tetra Society of North America}

"People are not limited by disability, but rather by obstacles and barriers in their environment." - Sam Sullivan, O.C., Founder of the Tetra Society.

It's a simple concept: rather than focusing on an individual's disabilities, look instead at the things that are stopping them from doing what they want to do, and find a way to overcome these barriers. For many people with physical disabilities, independence is often achieved with the help of technical devices that assist in everyday activities. The problem, however, is that many devices are either too expensive, not suited to an individual's specific needs, or simply do not exist commercially. Enter the Tetra Society of North America. Tetra is an award winning innovative charity that matches volunteer engineers/technicians and health professionals with persons with disabilities, with the goal of creating a low-cost device that provides greater independence, improve quality of life, or eliminates obstacles in the disabled person's environment. Tetra thus fills an important gap in the health delivery system for people with disabilities particularly in the area that addresses quality of life.

The Tetra Society of North America was founded by Sam Sullivan O.C. (former Mayor of Vancouver) in 1987 who became a quadriplegic following a skiing accident in 1979. Sam's idea for the society began from experiences he had following his accident 
revolving around physical accessibility and the lack of suitable daily living aids that adequately met his needs as an individual. Sam set out to find assistance that would enable him to make the apartment he loved so much accessible to his specific requirements. For his part, Sam thought that the help that he needed must surely exist. He soon found out, to his dismay that it was not. Determined not to become dependent on the social safety net, he first set out to solve his own unique set of problems. It was during this quest of enabling that Sam was introduced to retired engineer Paul Cermak PEng through the APEGBC. He partnered with Sam to make his bathroom more accessible. The final result: a bathroom that Sam could use independently. It was due to this successful partnership and results that Sam began to realize the benefit of having access to this technical knowledge and technology. It was from this realization that the vision of the Tetra Society of North America was born.

Tetra's greatest strength is that everything is conducted within the community. It is volunteerism operating at the local level, to meet an individual's unique needs. Tetra operates via a series of chapters, aided by head office in Vancouver, BC. Chapters comprise of a small group of volunteers, led by a coordinator. Presently, more than 500 Tetra volunteers are organized into about 50 Chapters across North America, and as far away as Bombay, India. Over the years, Tetra volunteers have completed more than 5,000 projects, ranging in complexity from a door opener fashioned from a coat hanger to a clock designed to display time as a bar graph. More examples of projects completed by the society can be found at the society's website www.tetrasociety.org. The St. John's Chapter was founded by the author in 1996 and it is the only chapter based at an engineering faculty of a university. This has provided easy access to skilled technical volunteers (students, faculty members, and technicians) and extensive workshop facilities. The St. John's chapter do not charge its clients for its services. All funding for materials comes from donations to the chapter by various organizations and foundations and from individuals or satisfied clients.

The Tetra process is client-driven. Someone contacts the organization requesting an assistive device to overcome a particular problem they experience. They are directed to complete a Request for Assistance (RFA) form which will be reviewed by the coordinator, and the work assigned to the best-fit volunteer. He or she will then meet the client or caregiver to consider the appropriate course of action. At each step along the way there is the opportunity for brainstorming sessions during the chapter's monthly meetings. The volunteer then design and constructs the assistive device and tests it with the client to ensure that it is safe and helpful.

Tetra's assistive device projects tackle barriers to mobility, personal care, and communications. They facilitate education, work and recreation. They provide increased access within households - kitchens, bedrooms and bathrooms - and other environments, such as vehicles or places of business. In short, assistive devices created by Tetra focus on improving quality of life. Tetra does not compete with commercially available products although it may design a much simpler or less expensive version of the product. Tetra also will not handle projects where there is funding available to hire rehabilitation engineers, OT, or other health professionals. Tetra tends to handle cases where others have given up.

The Tetra Society of North America was the winner of the Peter F. Drucker Award for the Most Innovative Charity in Canada in 1994, and the St. John's Chapter was the winner of the Provincial Citation Award of the Canadian Association of Occupational Therapists for Contributions to Rehabilitation Endeavours in 2003.

\section{First-Year Design Course}

All engineering programs across Canada typically have an introductory course (first year) in engineering design where the students are introduced to the process of engineering design. This is often a common course taken by all engineering students regardless of discipline. The introductory design course at MUN is generally along the same lines but usually with slight modifications depending on the instructor. The course over the last few years has tried to integrate the business, engineering design and graphics, and prototyping functions of a firm in creating a new product. It is intended to provide students with the following benefits: competence with a set of tools and methods for product design and development; confidence in their own abilities to tackle open-ended design problems; awareness of the cross-disciplinary nature of product development (e.g. marketing, finance, industrial design, business planning, prototyping, manufacturing, etc); structured practice in project management; and familiarity with the fundamental nature of engineering design. Students are expected to work in teams on projects that are either self-generated or assigned by the instructor. 


\subsection{Structure of the Design Course}

The first year engineering design course at MUN is called Engineering 1030 Engineering Graphics and Design. As the name suggests it consists of two interconnected parts; engineering graphics, with heavy emphasis on the use of Solid Works; and engineering design with lectures on various topics pertaining to design culminating in a team design project and public presentation. In addition, students also attend hands on workshops such as lathe work, metalworking, soldering, and taking apart and putting together a lawnmower. Fifty percent of the course marks go to the graphics component and the rest to the design component. Both components have a final exam.

The purpose of the lectures is to provide the tools, techniques, and guidance for the design and development process. Sample lecture topics over the years included:

- Design processes and organization: a discussion of science versus engineering, the product development process versus design, the challenges and rewards of product design and development, and basic project management

- Mission statement and identifying customer needs: mission statements and their uses, steps involved in identifying customer needs, guidelines for writing needs statements, and exercises in needs translation.

- Product specifications: what are specifications, steps in establishing target specifications, final specifications, steps involved in final specifications, and exercises in establishing specifications.

- Concept generation: activity of concept generation, steps in concept generation, common dysfunctions during concept generation, methods of concept generation and exercises.

- Concept selection and testing: overview of methodology for concept selection, concept screening and scoring, decision analysis, steps involved in concept testing, concept communication, measuring customer response, judging potential sales, examples and exercises.

- Intellectual Property (IP): what is IP, why is IP important, types of IP, IP relevant to product design, overview of patents, steps in preparing a disclosure, common mistakes with regard to patenting an invention, IP resources, costs involved in obtaining a patent, and conducting patent searches.

- Industrial design (ID) and prototyping: what is ID, critical goals for ID, how important is ID to a product, ID resources, types of prototypes, uses of prototypes, physical versus analytical prototypes, prototyping strategy, rapid prototyping methods, virtual prototypes and traditional methods, and steps in planning for prototypes.

The lectures are typically given by the course instructor, although "experts" are brought in wherever possible. These individuals were also available for consultations throughout the duration of the course. Lecture notes are provided in full on the course web site in addition to links to many useful web resources.

The culmination of the Engineering 1030 is the "capstone" design project where the students are expected to apply what they have learned in the course to complete the project. The students are formed into groups of 5 or 6 and they have about 3 weeks to complete the project followed by a public presentation by each design group.

It is quite difficult to assign meaningful open-ended design projects in a first year design course such as Engineering 1030. Students are fresh out of high school and have little technical knowledge or skills. Hence projects are often contrived and at the end, the project is just another exercise in the design process and has no lasting impact on anyone except maybe the students if they get a reasonable grade or fail the course. To make design projects more meaningful, it is important that students are given open-ended design projects that are doable, needed, and if successful would be of great benefit to an actual client. Students working on these projects would definitely be more motivated because of the real need of an actual client who is depending on them for a solution. It is with this motivation that instructors of the first-year design course at MUN have teamed up with the local chapter of the Tetra Society of North America to provide such open-ended design projects. These projects are actual requests from Tetra clients that have been submitted to the local chapter of the Tetra Society. Currently not all design groups take on Tetra projects. Some prefer to take on projects that have been assigned by other faculty members or the instructor.

\section{Sample Tetra projects}

The initial point of contact for the design teams is the Tetra coordinator who will meet with each group to describe the nature of the client's disability, what he/she is able to do, and what he/she needs. Photos and videos of the client in action may also be shown to the students. Contact information of other Tetra volunteers and occupational therapists familiar with the client will also be provided. It is expected that the team finds out as much as possible about the nature of 
the disability before embarking on the design. This could be diseases such as multiple sclerosis, cerebral palsy, and various forms of spinal cord injuries as a result of accidents. In some cases, they may need to meet or communicate with the clients and with the client's occupational therapist or physiotherapist for additional information. The students are also encouraged to consult the technical staff of MUN's Technical Services to make sure that what they propose as a solution is actually feasible. The final selection of the design to be actually fabricated is done by the Tetra Coordinator together with the client and/or care giver. The students are not expected to fabricate the final product but they are expected to provide the full technical drawings in Solid Works (both 2-D and 3-D CAD drawings) so that Technical Services can fabricate what is intended from the drawings. Cost is not really an issue. If the idea is feasible and suited the client's needs, then the cost of material and fabrication is covered by Tetra. A sample of four Tetra projects that have been assigned to students in Engineering 1030 over the last few years are briefly described below.

\section{Page turner for magazines}

This project was perhaps the most technically challenging of all the projects from the Tetra Society over the years. Although there are page-turning devices available in the market, but because of the client's specific disability none of the existing devices is suitable. The client is a well-known author and is now a quadriplegic and bed-ridden as a result of a serious car accident several years ago. He continues to write using voice recognition software. However, his greatest desire is to be able to read magazines such as Time, Newsweek, and Maclean, independently. He has very limited mobility. He can turn his head only a few degrees to the left and right and he can operate a computer mouse that is put on his chest as he has very little hand movements. He cannot sit up and his head is only slight propped up. Any device must be operated over his bed.

Over the years, the students have come up with various possible solutions for the problem. Tetra has also assigned this project as a final year capstone project to the mechanical engineering students. However, to date, no suitable solution has been found that meets his specific needs.

\section{TV remote control for client with $M S$}

This project is for an elderly female client with multiple sclerosis or MS. The disease is progressive and it has affected her ability to control her limbs. She has limited strength in her left and right arm although she is currently able to grasp light objects and able to control the joystick on her power wheel chair. She has very little fine motor skills. Among many other assistive devices, she would like to be able to control her television independently. She is not able to use the $\mathrm{TV}$ remote control because it requires quite a bit of dexterity to change the volume or channel. Currently, once her TV is set to a certain channel by her caregiver, she is stuck with the same channel unless someone else changes it for her.

The design team must always keep in mind the physical limitations of the client. That is, what she can and cannot do. Also, they have to be aware of where they can physically install the device on the wheelchair tray and whether it will impede other functions of the wheelchair. In general, most groups defined the problem and constraints very well. They correctly identify the components of the design such as methods to attach to the wheelchair, material to use, method of operation (lever, scroll ball, etc.) and how the operation is initiated (push a button, move a joystick, etc). From this they obtained hundreds of possible concepts through a concept combination table. The most promising concepts were selected using concept scoring and a pairwise ranking matrix. Testing the concept is done either by the Tetra coordinator and if possible the client themselves.

This project is currently on hold as the client has undergone a series of medical procedures to help her MS symptoms. It is likely that some constraints may hopefully be relaxed after her medical procedures.

\section{Walker for One-Handed Operation}

This next project is for a client who is in her late 50s who has suffered a stroke that paralysed her left side. Although she could get around using a cane, she was only able to walk short distances. Her daughter bought her a walker (similar to the one shown in Figure 1) so that she could maintain her independence. The problem was keeping in a straight line when pushing the walker with only her right arm and operating the brakes, which had two handles.

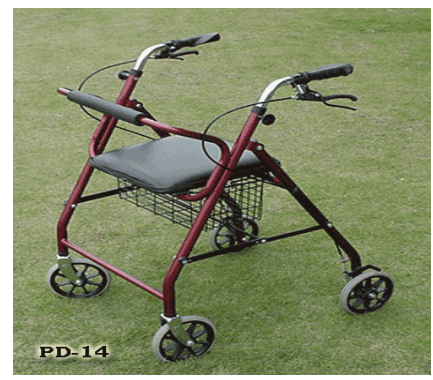

Figure 1: Standard walker 
In this particular project, the client met with the students during one afternoon so that she can explain her needs to the students. She also demonstrated how the walker is unsuitable without modifications. In simple terms all she needs is a modification that would allow her to use the walker one-handed (pushing and braking) and access the seat whenever she needed a short rest.

As usual many concepts were considered and compared. The client and the occupational therapist were also consulted to make sure that the design meets her needs. The final solution that was picked was a very simple solution with only a few modifications. Two bars were attached across the top of the walker. The top bar is for pushing the walker, which enables the client to push at the centre of the walker so it keeps in a straight line. The second bar is attached to connect the left and right brakes and allows her to control these together with a squeeze of the top and bottom bars. These bars however blocked access to the seat. To solve this problem, the back seat support was removed and turned around. The seat now faces in the opposite direction, to all intents being on the front of the unit, but is perfectly accessible by the client. The modified walker is shown in Figure 2.

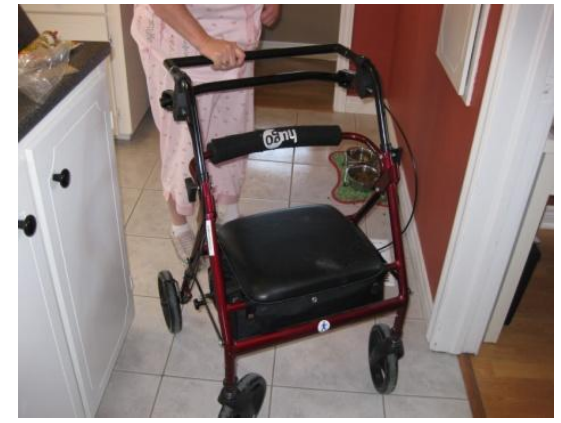

Figure 2: Modified Walker

The client was naturally very happy with the modified walker and can now take longer walks with her daughter and also walk her dog. She can also use it in her own home or in the garden.

\section{Braking system for garden cart}

Following the success of the walker project, the same client submitted another request to Tetra. To help with her gardening, her daughter bought her a garden cart shown below in Figure 3. She can position the cart to a spot in the garden and then sit on the cart to do her gardening. One problem with the cart is that it has no brakes. That means it may roll around and may cause her to fall over. This is of course a serious safety issue.

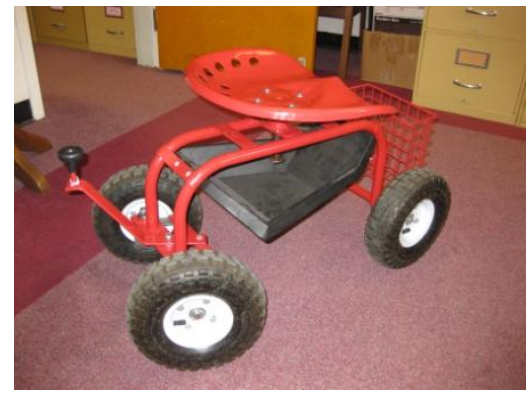

Figure 3: Garden Cart

The students were told that the braking system has to be simple to install and operate and must be able to be operated with one hand as the client can only use her right arm and hands. The students have access to the actual cart so that they can do detailed measurements and actually get to try and use it so that they get a better appreciation of the client's problem. Several groups took up the challenge and as usual numerous possible concepts were considered. Detailed fabrication drawings of their final design are expected as part of their project submission. This includes assembly drawings, 3-D drawings, parts list, etc. Figure 4 shows a sample of a detailed drawing by one of the groups.

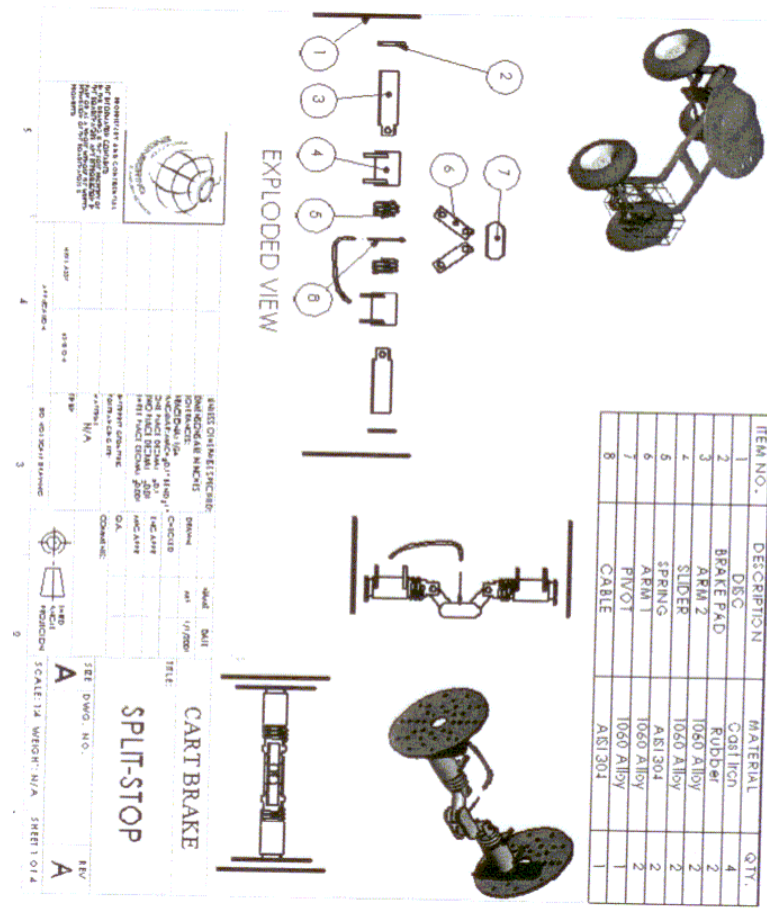

Figure 4: Sample detailed drawing of garden cart braking system. 
The final decision as to which design is the most appropriate for the client is pending the approval of the client. In addition, a few modifications may be necessary to the selected design during fabrication and testing.

\section{Conclusion}

From the feedback of students, instructors, and clients, the collaboration with the Tetra Society has been very successful in providing real, needed, design projects for first year engineering students. What is particularly valuable is the fact that students are asked to design something that is actually for a real client and the client are depending on them for a solution. As such the students are extremely motivated especially after they have met and talk to the clients. They learn about various diseases and disabilities and when the design gets implemented, they can be proud of their achievement and also their contribution to a very worthy cause. Some students would continue to volunteer with the Tetra Society and take on new projects.

As with any design project, there are always certain difficulties or issues with the project aside from personality, teamwork or other logistical problems. Tetra projects are no exception. One of the recurring issues is finding a suitable project at the time when the design course is offered. Another issue is that the project assigned may be just too difficult although at first glance it may not seem so. In terms of the solutions offered by the students, one recurring issue is the lack of details. For the solution to be useful to the client, someone from Tetra has to take over the project to get it fabricated. As such every detail needs to be worked out. A common question asked the students is: What's the budget? Unlike typical engineering projects where the solution is known and hence a detailed budget can be worked out, Tetra projects cannot be priced until there is a solution. Thus even if a budget of a billion dollars is available, it does not make any difference if there is no solution that is suitable for the client.

There are Tetra chapters in almost every major city in Canada. It would be very beneficial for universities to get in touch with them both as a source for projects and also for engineering students and faculty members to volunteer their time and lend their expertise. Better still if a university based chapter can be formed in cases where the Tetra chapters are far away from campus. Tetra is perhaps the only charity in Canada that is of an engineering type. Hence the link between Tetra and engineering schools should be strengthened and encouraged. This will also be of great interest to engineering students looking to a career in biomedical engineering or just to use their "MacGyver" skills.

\section{Acknowledgement}

I would like to thank Andy Fisher, John Tucker, Steve Bruneau, and James Yang, instructors of the first-year design course who have taken on Tetra projects over the years. The support of the Technical Services, MUN for their unwavering support of Tetra since 1996 is also gratefully acknowledged. Finally, I would like to thank all the students and volunteers who share and believe in the valuable work of the Tetra Society.

\section{References}

www.tetrasociety.org website accessed May 1, 2011.

The website contains contact information for all chapters in North America, request for assistance form, starting a chapter, funding, etc. and provides a repository of thousands of completed Tetra projects. 